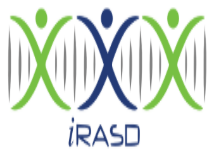

iRASD Journal of Management

Volume 3, Number 3, 2021, Pages 429 - 447

Journal Homepage:

https://journals.internationalrasd.org/index.php/jom

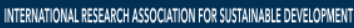

\title{
The Mediating Role of Affective Commitment between Creative Self- Efficacy, Authentic Leadership and Innovative Behaviour among Academic Employees of Higher Education Sector of Punjab, Pakistan
}

\author{
Tasawar Javed ${ }^{1}$, Shanayyara Mahmood ${ }^{2}$, Saadia Khan ${ }^{3}$, Habib Ullah ${ }^{4}$ \\ ${ }^{1}$ Assistant Professor, IBMAS, The Islamia University of Bahawalpur, Pakistan. Email: tasawar.javed@iub.edu.pk \\ ${ }^{2}$ Assistant Professor, IBMAS, The Islamia University of Bahawalpur, Pakistan. \\ ${ }^{3}$ Lecturer, IBMAS, The Islamia University of Bahawalpur, Pakistan. \\ ${ }^{4}$ Assistant Registrar, Advanced Studies and Research Board, PhD scholar, The Islamia University of Bahawalpur, \\ Pakistan.
}

\section{ARTICLE INFO}

\section{Article History:}

Received:

Revised:

Accepted:

November 26, 2021

Available Online: December 31, 2021

\section{Keywords:}

Creative Self-efficacy

Authentic leadership

Affective commitment

Innovative Behaviour

\section{ABSTRACT}

The higher education sector in developing counties has undergone through dynamic changes in recent era due to highly innovative and competitive environment. The phenomenon of innovation behaviour has gained intensive importance due to its long-lasting impact on performance of industry. The growth of knowledge-based economy is linked with innovative initiatives of employees of higher education sector. The proposed research contributes to the body of knowledge by explaining the relationship between exogenous constructs and innovative behaviour based on the theories of social exchange and social cognition as both theories explains the innovative behaviour of employees. The proposed research intends to bridge the research gap and inconclusive results between constructs to explain the innovative behaviour of academic employees of higher education sector. Moreover, the mediation role of affective commitment is incorporated for deeper insight of innovative behaviour. The data was obtained from academic employees of the public sector universities of Punjab, Pakistan through simple random sampling and was analysed on Smart-PLS. The authentic leadership considered as one of the crucially important factors at workplace that influence the affective commitment and innovative behaviour. The study reported significant results for hypothesis $\mathrm{H} 1$ that affective commitment influences the innovative behaviour, the hypothesis $\mathrm{H} 2$ reported that creative self-efficacy influences the innovative behaviour, they hypothesis $\mathrm{H} 3$ reports that authentic leadership influence the innovative behaviour. The hypothesis $\mathrm{H} 4$ depicts that creative self-efficacy influences the affective commitment, the hypothesis $\mathrm{H} 5$ found that authentic leadership influences the affective commitment. Similarly, the mediation role of affective commitment reported as significant between authentic leadership and innovative behaviour, however no mediation role of affective commitment was reported between creative self-efficacy and innovative behaviour. The findings of the study assist universities management to ensure the appropriate and supportive workplace initiatives for inclined innovative behaviours among employees. The future study may be conducted on comparison of highly innovative universities and less innovative educational institutes.

(C) 2021 The Authors, Published by iRASD. This is an Open Access article under the Creative Common Attribution Non-Commercial 4.0

Corresponding Author's Email: tasawar.javed@iub.edu.pk 


\section{Introduction and Background}

The higher education sector vitally contributes in educational services through knowledge enrichment, endorse innovative initiatives and create human capital for nation to gain competitive advantages. The numerous issues and challenges have been faced by higher education sector in highly competitive environment in fulfilling the demand of market and clients to provide their educational services (S. J. Al-Husseini \& Dosa, 2016). The tertiary level educational institutes required to sustain higher quality of education that critically play role in economic growth. The academic staff of universities considered as source of experience, knowledge, skills and abilities that enhance educational quality and intensify the workforce for countrywide development (S. Al-Husseini, El Beltagi, \& Moizer, 2019; Elrehail, Emeagwali, Alsaad, \& Alzghoul, 2018). The behaviour of academic staff has crucial importance in working environment, performance of organizations and continuous development while achievement of sustained growth (Fullwood, Rowley, \& Delbridge, 2013). Currently, the academic institutes are expected to innovate through effective performance, so therefore innovative behaviour of academic staff gains attention due to its impact educational services and outcomes. Undoubtedly, academic staff possesses unique skills, abilities, knowledge and techniques that depicts the level of their contribution in institutes to gain expected objectives (S. Al-Husseini et al., 2019). The immense influence of employees' behaviour on organizational performance, effectiveness and sustainability has been observed in literature empirically. The innovative behaviour refers to emergence of new ideas while being multitasking and motivational forces among participants of the organizations (Nazir, Shafi, Atif, Qun, \& Abdullah, 2019).

The innovative behaviour of employees contributes in initiating innovation in processes and operations as required in highly competitive environment by implementing the innovative solutions for enhancing the performance and competitive advantages (Javed, Khan, \& Quratulain, 2018) (Javed et al., 2018). Further, innovative behaviour has been elaborated as capabilities of employees to generate innovative solutions to problems through novel thinking processes while exerting extra ordinary efforts to gain organizational performance, excellence and long-term effectiveness. Previous research scholars have described IB (Innovative behaviour) as positive attitude of employees to work beyond responsibilities in perception of exchange relationship with organizations as underpinned by social exchange theory. The social exchange considered as reciprocity rule that one person does a favor and expect to have good in return based on the discretion of the one who makes it (Nazir et al., 2019).

The research scholars have explained the phenomenon of innovative work behaviour as a dynamic, multifaceted and creativity that entails the interrelated attributes for acknowledging various issues, concept creation, promotion and recognition. The projection of newly emerging ideas, creativity-oriented tasks and behaviours to gain the competitive advantages in the current market based on imperative, creative, innovative and competitiveness. The organizations seek to innovate the production techniques for gaining the competitive edge by reducing the cost, increasing the quality and to develop the fruitful behaviour of employees for desired consequences. The education-related field has been recognized globally as per establishment of the innovative work behaviour with the introduction of IT and emergence of electronic business means. To comply with advanced technological initiatives the innovative work behaviour must be increased among employees, so that education sector and leadership plays crucial and important role in advancing the behavioural perspective (Javed et al., 2018). The leadership style plays vital role in organizational development and circumstances for currently present issues and future perspective. The organizational citizenship behaviour entails the required behaviour of employees demanded by leaders for attainment of goals and targets towards customer satisfaction. The organizations make sure to assist new employees to enhance the workflow, additional hours, contributing in corporate events and giving useful suggestion for development (Ja'afaru Bambale, 2014). The prior literature has expressed that leadership style has the tendency to improve the organizational culture for best interest of organization, retain the desired cultural aspects and influence the innovativeness of the behaviour of employees by sharing the values and ideas (Naqshbandi \& Tabche, 2018). The leadership influence the culture of organization that introduce the innovative initiatives and contribute in the progress innovation, so therefore, it is important to consider the leadership styles including transformational and transactional leadership styles that 
influence the innovation and creativity at workplace. The disagreement among authors have been identified in assessing the influence of leadership styles on innovation and innovative work behaviour in higher education sector of Pakistan (Javed et al., 2018; Jia, Chen, Mei, \& $\mathrm{Wu}, 2018)$.

The previous study conducted on the education sector of Pakistan reported that transformational and transactional leadership style influence the innovative work behaviour, but the lassiez-faire leadership style found to be insignificant towards innovative work behaviour. Moreover, the organizational citizenship behaviour significantly mediates the relationship between transactional, transformational leadership style and innovative work behaviour. Further, the significant moderation role of organizational citizenship behaviour has been observed between transactional, transformational leadership styles and innovative work behaviour (M. A. Khan, Ismail, Hussain, \& Alghazali, 2020). Previously, the research has been focused on the impact of knowledge management on creativity of employees in public sector libraries' professionals in universities in Pakistan. The study argued that knowledge creations, knowledge implementation, knowledge storage, and knowledge sharing influence the creativity level of the employees working in the public sector universities in libraries. The results of the study reported that knowledge creation, knowledge implementation, knowledge sharing and knowledge storage significantly influence the creativity of the employees, so therefore the knowledge management must be taken into account for increase the creativity among employees (Rahoo, Baladi, Yasmeen, Khan, \& Bhutto, 2020). However, study was limited to the province of Sindh in Pakistan, further the study focused only knowledge management to explain the phenomenon of creativity among employees as it overlooked the other important variables that influence the innovativeness and creativity.

Another research effort determined the employee innovation influenced by work life imbalance, climate for innovation, and inter role conflict among the research scholars of universities in Lahore, Pakistan. The study reported that work life imbalance significantly influences the employee innovation, further the climate for innovation also found to be significant in explaining the employee innovation, but inter role conflict observed to be insignificant in explaining the employee innovation (Ahmed \& Ahmed, 2015). That means work life imbalance and climate for innovation must be incorporated at workplace among employees to ensure the creativity and innovation, however the literature argued that inter role conflicts must be resolved in order to increase the employee innovation. The research studies have affirmed predictors of innovative behaviour in diverse context as innovative behaviour believed to be increase in knowledge generation, skills enhancement and quality of education (Zhou \& Velamuri, 2018). The influence of leadership has been observed on innovative behaviour in Malaysian study with mediation role of creative self-efficacy (Ibusa, Wahabb, Ismailc, \& Omard, 2020a). The concept of 'self-efficacy' refers to 'capabilities to deliver required objectives and achievement' of employees based on cognitive processes of individuals to perform a task (Bandura, Freeman, \& Lightsey, 1999). Further, it has been asserted that self-efficacy influences the undertaken job to be fulfilled, it also persuades efforts to successful accomplishment of task with utilization of abilities and influence response of successful completion of task. Social cognitive theory posits that personal, behavioural and environmental influences affect the human functioning at workplace. The personal factors including cognition abilities, physiological events and effect, behaviours and manners play vital role in human behaviour and functions. It is believed to be distinct than learning theories that influence the cognition, environment and behaviour. It has been argued that change in behaviour effect the change in self and environment that further affect the behavioural changes (Newman, Herman, Schwarz, \& Nielsen, 2018). The previous studies have investigated the role of self-efficacy to determine the behaviour of employees including innovation capabilities with effect of entrepreneurship and reported significant findings (M. S. Mehmood, Jian, \& Gilal, 2020). The study of Newman et al. (2018) depicted positive significant results between self-efficacy and innovative behaviour among Chinese employees.

Innovative behaviour of employees observed to be influenced by various factors as leadership found to be one of the most striking variables among employees of UAE (Darwish, Zeng, Rezaei Zadeh, \& Haak-Saheem, 2020). Further, the influence of supervisor supportiveness also significantly impacts the innovative behaviour among nurses of Turkish 
hospitals (Sönmez \& Yıldırım, 2019). The study of M. A. Khan et al. (2020) conducted on Pakistani education sector reported that industry has faced leadership dilemma and failed to achieve required objectives while indulged in nepotism, favouritism and injustice. The findings of the study depicted that transaction and transformation leadership styles significantly influence the innovative behaviour among employees of higher education sector. Similarly, the leadership styles (transformational and participative behaviours) significantly predict the innovative behaviour among Chinese workforce (Newman et al., 2018). The study conducted on Malaysian employees also reported significant influence of self-leadership to predict innovative work behaviour (Ibusa et al., 2020a). The above recent studies imply that leadership play vital role in education sector for influencing the behaviour of employees. The studies have focused on leadership styles including transformational, transactional and participative leadership style among diverse industries and considered Western countries to investigate the relationship, however prior studies have overlooked the role of authentic leadership to predict the employees' behaviour.

The current study incorporated the creative self-efficacy to explain the innovative behaviour of employees, as the perception of an individual about oneself of performing creative tasks. The creative tasks are more likely to be performed through cognitive and motivational perspective of an employee that depicts the creative self-efficacy. The effort of individuals by time believed to be producing the desired consequences as social cognitive theory argues also explain the phenomenon of innovative work behaviour influenced by self-efficacy and creativity of the employees (M. S. Mehmood et al., 2020). The prior literature has stated positive relationship between creative self-efficacy and creative outcomes, studies also incorporated the individual and contextual factors to explain the creativity and innovativeness (Cai, Lysova, Khapova, \& Bossink, 2019). The literature has argued that leadership styles found to be influential in increasing the creative self-efficacy through inspiration, encouraging and acting as the role models for employees, as entrepreneurial leadership observed to valuable factor towards the innovative work behaviour. The prior research also suggested to explain the phenomenon of innovative behaviour through effect of leadership styles and other relevant factors (Afsar \& Masood, 2018). It has been reported that creative self-efficacy recently emerged from the field of creativity as the creative employment is needed in every sector to undertake the creative initiatives. The creativity influences the performance and motivation in every field as creative self-efficacy considered as mental apparatus that influence the creativity (Abdullah, Ashraf, \& Sarfraz, 2017). The prior literature empirically investigated the influence of cultural intelligence on job satisfaction, turnover intention and self-efficacy, the study revealed that cultural intelligence influence the self-efficacy significantly, the satisfaction also reported as significant predictor of self-efficacy, further satisfaction mediates the relationship between cultural intelligence and self-efficacy. The prior literature stressed upon investigating the predictors of self-efficacy and suggested to examine the influence of self-efficacy on behavioural outcomes (AlMazrouei \& Zacca, 2020).

The affective commitment refers to the positive feelings of identification, attachment and involvement of an individual to the organization. The affective commitment is derived from the concept of organizational commitment that referred the psychological state of employees and their relationship with the organization to influence intention to remain or leave the membership of the organization. The emotional attachment of employees to the organization, the identification with the workplace and involvement in organizational activities referred as affective commitment. The research scholars have expressed organizational commitment through social exchange theory that commitment of employees depends upon the relationship between employees and organization, the higher the level of recognition and emotional attachment the higher the affective commitment (Tahir, Hadi, \& Awan, 2021). The research scholars have focused upon the organizational commitment due to its crucial importance as emotional attachment to the organization leaves long lasting impact on behaviour of employees. The employee performance is assessed through the commitment of employees, the turnover of employees also related with the organizational commitment, the absenteeism of employees and efficiency of employees have been related to the organizational commitment. The research scholars have explained the determinants of the commitment in terms of individual characteristics, job role, structural features and job experience, while outcomes of commitment include performance, attendance, reduced turnover and seniority (N. Mehmood, Ungku, Irum, \& Ashfaq, 2016). 
The current study intends to determine the innovative behaviour of university employees influenced by creative self-efficacy, authentic leadership and affective commitment as mediating construct. The objectives of the study are three-fold, first to determine the relationship between creative self-efficacy and affective commitment and innovative behaviour. Second, the relationship between authentic leadership and innovative behaviour and affective commitment. Thirdly, the mediating role of affective commitment between creative self-efficacy, authentic leadership and innovative behaviour. The study incorporates the academic employees of the public sector universities of Punjab, Pakistan.

\section{Literature Review}

Innovative behaviour of employees referred as unique activities related to developmental aspect, promotion and execution of strategies at organizational level that influence sustainability and performance. The innovative behaviour of employees described as emergence of new ideas, adoption of technology and techniques, implementation and execution of newly developed systems and applications for business operations. Prior studies have highlighted the significant role of innovative behaviour in various sectors to deliver reliable high-quality business or services operations. The role of innovative behaviour found to be effective in organizational performance and success among nurses at hospitals of Turkey (Sönmez \& Yıldırım, 2019). The research scholars have related innovative behaviour with improvement in ideas that gauge the innovation level and enhance the performance. The innovative behaviour leads towards the accomplishment of goals as it depends upon the higher level of education. The previous research studies related innovative behaviour with exploration of opportunities, generating ideas, implementation and execution of ideas that can lead towards organizational success and performance (Devloo, Anseel, De Beuckelaer, \& Salanova, 2015). The studies have translated innovative behaviour in education sector that relates to the teaching practices while keeping in view the capabilities of teachers, strengths of academic staff, identification of weakness of teachers and the plan to enhance the knowledge, skills and abilities of academic staff to enrich the performance, quality of education and equip graduates with required knowledge and skills (Bawuro et al., 2020; Kaur \& Gupta, 2016).

\subsection{Affective Commitment and Innovative Behaviour}

The term affective commitment referred to the emotional attachment of employees and their involvement in organization that found to be having passionate relation with workers, desire to see the organizational success and to gain the pride of being part of organization. The current study incorporated the affective commitment due to its significance influence on workplace environment and impact the behaviour of employees, in short the affective commitment influence the organizational identification and personal identification, so therefore prior studies encouraged to conduct the studies on affective commitment ( $\mathrm{Fu}, \mathrm{Ye}, \& \mathrm{Law}, 2014$ ). It has been highlighted that organizational commitment is psychological state related to the association among employer and employees. The prior research studies have addressed the concept of organizational commitment in detail that how an employee can become affective as it referred as emotional attachment towards the work and organizations. The studies have reported negative relationship between affective commitment and turnover intention and positive relationship with performance (Meyer, Stanley, Herscovitch, \& Topolnytsky, 2002). If the workplace is perceived as positive by employees that is highly expected that employees will likely to stay in organization and will utilize their capabilities and put their efforts for organizational interest (Nazir et al., 2019). Further, it has been found that affectively committed employees expected to be more creative and found more innovative and demonstrate innovative behaviour. The affectively committed employees put extra efforts for organization to innovate and present greater concern for organizational well-being (Nazir et al., 2019).

Tang, Shao, and Chen (2019), acknowledged the importance of positive psychological state in influencing attitude, value and innovative behaviour which will contribute to the company's development and growth. Recently, it has been reported that affective organisational commitment mediates the relationship between leadership, justice and innovative behaviour (Khaola \& Coldwell, 2019). Nazir, Qun, Hui, and Shafi (2018) also confirmed the implications of perceived organisation support, leadership in cultivating 
affective commitment and prompting innovative behaviour. The study reported significant relationship between affective commitment and innovative behaviour, moreover the perceived organizational support mediated the relationship between affective commitment and innovative behaviour among IT sector employees of Pakistan (Nazir et al., 2019).

The research study has expressed the relationship between self-efficacy and affective commitment as results of the empirical evidence reported significant positive relationship among employees of Australian consulting organizations (Albrecht \& Marty, 2020). Another study examined the relationship between corporate social responsibility and affective commitment with mediation role of organizational trust and reported significant results in both direct and indirect affect to predict affective commitment among employees of Pakistani higher education sector (Ahmad, Ahmad, Islam, \& Kaleem, 2020). Recently, the study has been conducted on higher education sector to determine the employee's task performance predicted by pay satisfaction with moderation role of managerial support and mediation role of organizational commitment was investigated that reported significant positive results. The results demonstrated that pay satisfaction predicted employees' task performance through affective commitment (Khalid, 2020). The prior studies have expressed the influence of authentic leadership on creativity and affective commitment; it has been shown that authentic leadership drive the affective commitment through trust and other phenomenon (Paillé, 2009). The study reported that organizational climate develop the attachment among employees that enable them to put extra efforts to become innovative, creative and to strive for organizational success (Rego, Vitória, Magalhães, Ribeiro, \& e Cunha, 2013). Ribeiro, Duarte, Filipe, and Torres de Oliveira (2020) has depicted positive significant relationship between authentic leadership and affective commitment.

Hypothesis H1: Affective Commitment influence the Innovative behavior among employees of higher education sector of Pakistan

\subsection{Creative Self-efficacy and Innovative Behaviour}

The creative employment is indeed necessity for firms to originate creativity and innovation that plays pivotal role in enhancing the performance. The field of creativity has emerged with new concept of creative self-efficacy recently that found to be useful in influencing the creative initiatives and innovation in diverse field (Abdullah et al., 2017). The research scholars have expressed creative self-efficacy as mental capabilities for being creative while doing things differently, higher the creative self-efficacy the more engagement and creativity can be emerged that enable sustainability with the help of support and autonomy. The employees with higher creative self-efficacy believed to be leading the team and influence the performance (AlMazrouei \& Zacca, 2020). However, the performance of firms is not only depended on creative individual's self-efficacy but various other internal and external factors, the internal factors largely depend upon the employees and their capabilities and abilities to perform task innovatively. The firms utilize creative capabilities of employees and their self-efficacy enables firms to innovate to gain competitive advantages and sustainability (Abdullah et al., 2017).

The recent prior studies have reported relationship between creative self-efficacy and innovative behavior of employees in different countries and sectors. The study conducted on Chinese employees on multinational organizations to assess their innovative behavior and self-efficacy. The study reported significant positive results that creative selfefficacy influences the innovative behavior of employees. The study examined the moderation role of entrepreneurial leadership and reported significant results (Newman et al., 2018). However, study only examined the relationship between self-efficacy with moderation role of entrepreneurial leadership, while ignoring the other possible influential factors to explain the innovative behavior for deep understanding. The study conducted on education sector in Nigeria to assess the innovation behavior of teachers based on motivation, self-efficacy and social motivation and reported significant findings that teachers must be higher in creative self-efficacy in order to be innovative and enhance the quality of education and equip their graduates with higher level of knowledge, skills and abilities (Bawuro et al., 2020). Another recent study depicted significant influence of selfefficacy on innovative behavior private higher education institutes of Malaysia, the study 
also examined the self-leadership and mediating role of self-efficacy and found significant results (Ibusa et al., 2020a).

Based on recent research studies it has been evident empirically that creative selfefficacy has influence on innovative behavior of employees, however studies were limited with only one construct that is insufficient to determine the innovative behavior as it depends upon multiple factors. Moreover, the Saudi higher education public sector found to be lower in innovation and creativity. So therefore, there is dire need to assess the level of innovative behavior of academic staff while assessing their creative self-efficacy for development of policy for higher education sector.

Hypothesis H2: Creative Self-efficacy influence the Innovative behavior among employees of higher education sector of Pakistan

\subsection{Authentic Leadership and Innovative Behavior}

The current section of the study incorporated the previous literature about authentic leadership and its impact on behaviour of employees. The research scholars expressed authentic leadership as an approach to build legitimacy based on ethical, respect and honesty perspective. The authentic leadership related with openness and encouragement for building trust among colleagues for sharing that plays vital role in creativity and innovation. It has been depicted in recent research that authentic leadership has received little attention and needs to be incorporated in various working environment settings to determine its impact. The prior research studies have ignored the influence of authentic leadership on innovative behaviour, however other leadership styles such as transformational leadership (Nardo, Evanita, \& Syahrizal, 2019), transactional leadership (M. A. Khan et al., 2020), inclusive leadership (Qi, Liu, Wei, \& Hu, 2019), self-leadership (Ibusa et al., 2020a) and servant leadership (Karatepe, Aboramadan, \& Dahleez, 2020) has been empirically examined in detail with innovation behaviour. The education sectors has come across number of challenges and issues in today's global environment with higher competition, scarcity of funds, fluctuation in educational services, and survival related issues for acquiring competitive advantages on the base on innovation (Gaspar \& Mabic, 2015).

The innovation has become most crucial factor in survival and success of organizations including higher education sector, so therefore research scholars have exerted attention on leadership styles in determining the innovative behaviour and their capabilities of creativity. The leadership has emerged as one most important factor in educational institutes for affective innovation through generation of new ideas, setting the goals and objectives, and most importantly innovation seeking culture (Zhu, 2015). The prior studies have investigated the leadership in different perspective such as examined the transactional leadership, transformational leadership and lassiez-faire leadership to predict the innovative behaviour with mediation role of organizational culture and reported significant findings among education sector of Pakistan (M. A. Khan et al., 2020). The study conducted in Indonesian on travel industry to determine the innovative behaviour predicted by transformational leadership and work environment through work motivation that found significant results (Nardo et al., 2019). Another study conducted on Palestinian employees depicted positive results between servant leadership and management innovation and innovative behaviour with mediation role of climate of creativity (Karatepe et al., 2020). Another type of leadership emerged as inclusive leadership that leads towards innovative work behaviour as examined on employees of textile sector of Pakistan (Javed et al., 2018) and another study examined on Chinese employees (Qi et al., 2019); both studies reported significant results with mediation role of leader-member exchange and perceived organizational support respectively. These prior studies have overlooked the role and influence of authentic leadership to predict innovative behaviour.

The role of authentic leadership to predict employees' behaviour has been expressed by research scholars. Authentic leaders are considered as pro-active and future oriented, they focus on long term strategy. The recent study has investigated the role of authentic leadership in predicting the Intrapreneurial behaviour; the study also expressed relationship between authentic relationship and empowerment. The positive significant results have 
been reported as the study was conducted on higher education sector of Pakistan. The study focused on entrepreneurship and empowerment but overlooked the relationship with innovative behaviour. Contrary, the study conducted on Jordan private higher education sector reported insignificant results that authentic leadership do not predict and has no relationship with innovation in product or services (Elrehail et al., 2018). The current study intends to determine the relationship and role of authentic leadership and innovative behaviour due to two major lacks including paucity of study in determining the relationship between authentic leadership and innovative behaviour, and the existing research has reported contradictory results as presented above. Thus, the current study intends to determine the relationship between authentic leadership and innovative behaviour among public higher education sector of Pakistan.

Hypothesis H3: Authentic Leadership influence the Innovative behavior among employees of higher education sector of Pakistan

\subsection{Creative self-efficacy and Affective Commitment}

The belief of employees about capability to perform effectively and to attain the positive consequences, the judgement of an employee to perform the certain action that might turn in adoption and effort to be invested to continue in same situation referred as self-efficacy. It is also considered that context and situation of specific construct that entails the cognitive actions comes under the self-efficacy and literature has well documented the role of self-efficacy. The literature embarks on the role of self-efficacy to determine the motivation and performance along with transformational leadership and creativity (Lent, Ireland, Penn, Morris, \& Sappington, 2017). The prior research studies have identified that job satisfaction, motivation, learning intention, career commitment and productivity as consequences of self-efficacy. The higher success of the organization and individuals depends upon the situation and self-efficaciousness that comes from the hard working towards innovation that increase the performance directly (Çetin \& Aşkun, 2018).

The prior study indicated that self-efficacy influences the affective commitment significantly and influence the organizational citizenship behaviour among the employees of telecom and education sector (Erum, Abid, Contreras, \& Islam, 2020). The education sector strives to achieve sustainable development and various training and skill development programs have been undertaken for accomplishment of the goals and effective leadership is required for the purpose to attain sustainable development. The leadership of the institutes play important role in sustainable development and research studies have examined the role of leaders' self-efficacy and organizational commitment among Saudi universities. The study depicted positive association between self-efficacy and affective commitment and self-efficacy also influences the continuance commitment, further the leadership selfefficacy positively related to normative commitment that improve the organizational performance and faculty's innovative capabilities (Almutairi, 2020). Another research study conducted in Portugal investigated the individual performance through affective commitment influenced by authentic relationship, the results of the study depicted that affective commitment positively influence the individual performance, the authentic leadership also found to be positively related to affective commitment and individual performance, further affective commitment significantly mediates the relationship between authentic leadership and individual performance (Ribeiro, Gomes, \& Kurian, 2018). The current study argues on the base of previous literature that affective commitment influences the individual behavioural outcomes.

Hypothesis H4: Creative Self-Efficacy influence the Affective Commitment among employees of higher education sector of Pakistan

\subsection{Authentic Leadership and Affective Commitment}

The authentic leadership has been occurred in the literature that explained the behaviour of leaders that further promote the psychological capacities and positive ethical climate that foster the self-awareness, balance processing, relational transparency and encourage the self-development (Walumbwa, Avolio, Gardner, Wernsing, \& Peterson, 2008). The literature argues that committed employees stay longer in the organization and align their tasks with organizational goals. The authentic leadership plays crucial role in 
decision making for interaction with followers, consistency and performance, so therefore research scholars suggested to focus on leadership dimensions to demonstrate the affective commitment (Walumbwa, Cropanzano, \& Goldman, 2011). It has been well documented that authentic leadership demonstrate more respect, confidence and trust among the employees to gain the loyalty and commitment in order to accomplish the goals of the organizations through motivation. The emotional bond between employees and organization becomes stronger when employees perceive leaders as authentic, the social exchange theory (SET) posits the similar behaviour of employees that depends upon and reciprocal of mutual benefits between employees and organizations (Ribeiro et al., 2020; Ribeiro et al., 2018).

The quality of exchange between leaders and employees reciprocates the level of affective commitment. Thus, it has been found that authentic leaders ensure the highquality exchange between employees and organization through honest behaviour and level of information sharing among employees to gain the affective commitment of the employees (Allen-Ile, Mahembe, \& Balogun, 2020). The research scholars have found that authentic leadership significantly related with affective commitment because authentic leaders have the potential to exert beliefs, values and moral principles that predict the affective commitment of the employees (Alshammari, 2015; Johnson, Onwuegbuzie, \& Turner, 2007). Thus, leadership authenticity significantly relates to the emotional attachment and affective commitment of employees, so therefore the current study intends to determine the relationship between authentic leadership and affective commitment among higher education sector of Pakistan to explain the innovative behaviour.

Hypothesis H5: Authentic Leadership influence the Affective Commitment among employees of higher education sector of Pakistan

\subsection{Mediating Role of Affective Commitment}

The current study argues that creative self-efficacy influences the innovative behavior and affective commitment, and the authentic leadership also influences the innovative behavior and affective commitment, so therefore the current study intends to determine the mediating role of affective commitment between creative self-efficacy, authentic leadership and exogenous construct innovative behavior. The prior literature reported that affective commitment mediates the relationship between individual perception and transactions/investment such as benefits, reward, time, effort and salary. The study also reported significant relationship between affective commitment and individual behaviors and individual feelings (Mercurio, 2015). The study investigated the organizational citizenship behavior of banking sector employees in Pakistan and reported that person-organization-fit influence the affective commitment and significantly mediated by affective commitment between person-organization-fit and organizational citizenship behavior (Tahir et al., 2021). The previous study examined the affective commitment influenced by authentic leadership and psychological empowerment, the study reported that authentic leadership influence the affective commitment and psychological empowerment significantly, further the psychological empowerment significantly mediates the relationship between authentic leadership and affective commitment (Almutairi, 2020). The result of the study depicted that authentic leadership positive impact the affective commitment and creativity, the relationship between authentic leadership and creativity significantly mediated by affective commitment, the organizational leadership increase the affective commitment and creativity of the employees (Ribeiro et al., 2020).

Hypothesis H6: Affective Commitment mediates the relationship between creative selfefficacy and Innovative behavior among employees of higher education sector of Pakistan

Hypothesis H7: Affective Commitment mediates the relationship between authentic leadership and Innovative behavior among employees of higher education sector of Pakistan 


\section{Research Framework}

This section demonstrates the research framework to explain the innovative behavior of employees of higher education sector of Pakistan. The innovative behavior is assumed to be influenced by creative self-efficacy, authentic leadership and affective commitment, moreover the affective commitment mediates the relationship between exogenous and endogenous constructs. The following hypothesized relationships based on framework and literature has been derived to investigate the relationship between variables.

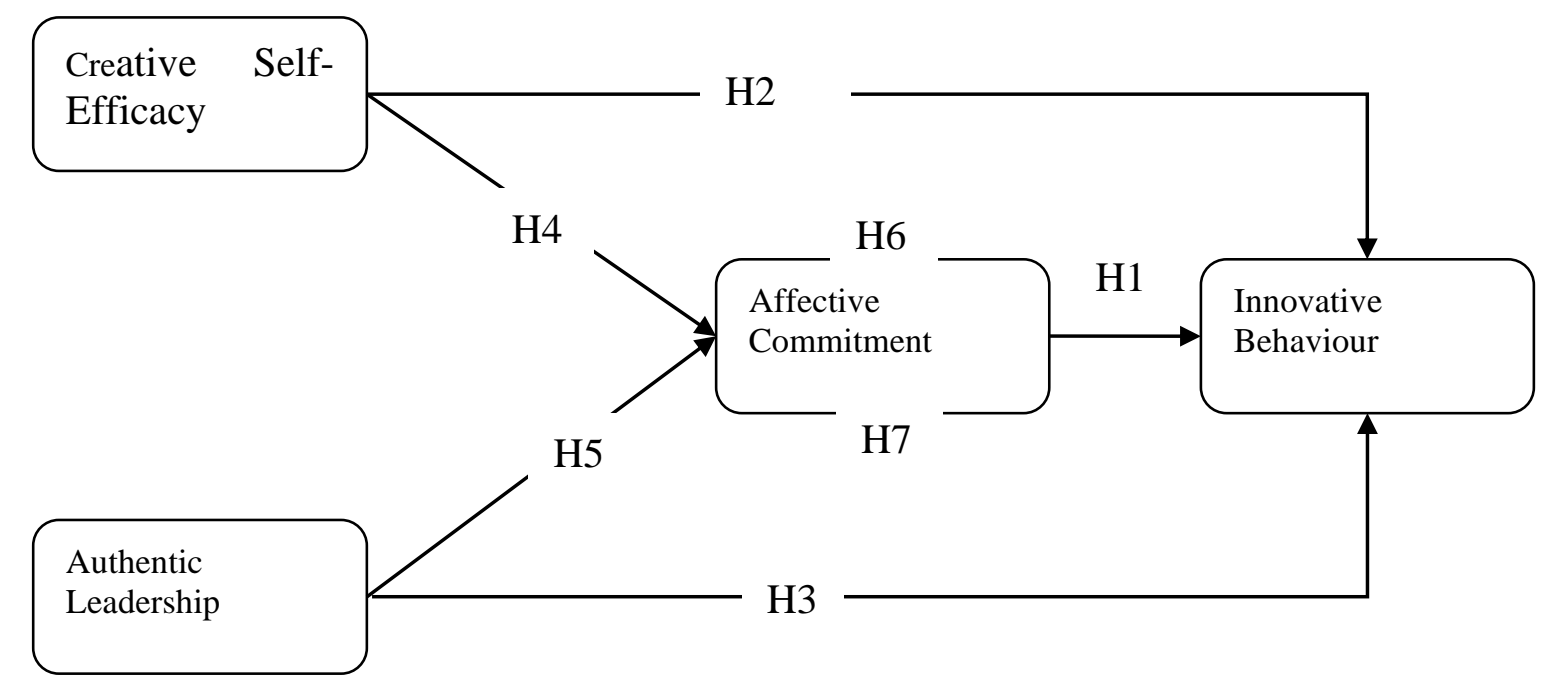

\section{Figure 1: Research Framework}

\subsection{Research Methodology}

The present research effort is quantitative in nature as data was collected from employees to assess the innovative behaviour through questionnaire. According to Sekaran and Bougie (2016), population is "related to an overall group of people or organization which might be of interest to the researcher". The population in the present study entails full time academic employees including lecturers, assistant professors, associate professors and professors. The researcher includes only full-time academic employees of public sector universities located in four different provinces and the federal territory capital (Islamabad) of Pakistan. According to the HEC (2020), there are 174 public and private sector universities of various categories. The statistics shows that there are 96 public sector universities of which $55 \%$ are total universities of Pakistan. A total of 156,880 teachers are currently serving in higher education institutes throughout the country. It has been established in previous studies that the academic staff in public sector universities in relatively homogenous groups generally adopt the structure of appointment by Government of Pakistan (Altaf, 2017; Javed \& Ishak, 2019). The total number of academic employees in the 43 universities according to the HEC (2019) is 16,131 consisting of lecturers, assistant professors, associate professors and professors.

The researcher considered Punjab and the federal territory for data collection as two clusters based on geographic regions. A total of 07 universities in the federal territory were chosen after stratified sampling with a population of 6099. A total of 12 universities were chosen after stratified sampling in the region of Punjab with a population of 7032 . The total population for the study in both regions is 13,131 . The current population of 13,131 in 19 universities represents $82 \%$ of the total population of the 43 universities. The simple random sampling technique was utilized for data collection from public sector universities of Punjab, the sample was drawn on the basis of (Krejcie \& Morgan, 1970) table and 380 was required sample to assess the relationship between constructs of the study. The total of 450 questionnaires were distributed in order to get the maximum responses, however total 209 complete responses were received and included in the analysis. 


\subsection{Measurement Instrument}

The measurement sale of each construct was adopted from prior literature and was assessed on the base of 5-point Likert scale from 1 to 5 , where 1 denotes strongly disagree, 2 disagree, 3 neutral, 4 as agree and 5 strongly agree. The measurement scale of creative self-efficacy consists of 04 items and adopted from the study of (Almutairi, 2020). The measurement scale of authentic leadership consists of 16 items and adopted from the research of (A. S. D. Semedo, Coelho, \& Ribeiro, 2016). The measurement scale of affective commitment was adopted from the study of (A. S. Semedo, Coelho, \& Ribeiro, 2019) with 06 items. The 09-items measurement scale of innovative behaviour was adopted from the work of (Janssen, 2000), the scale was derived and based on the original work of (Scott \& Bruce, 1994) that initially developed the five items for measuring innovativeness.

\section{Analysis and Discussion}

The analysis of the collected data was conducted on Smart-PLS by utilizing PLSalgorithm to assess the validity and reliability of the constructs through measure model assessment. The hypothesized relationship was assessed through bootstrapping method on PLS.

\subsection{Measurement Model Assessment}

This section presents the reliability and validity of the constructs based on collected data, the measurement model assessment demonstrates the Cronbach alpha, Composite reliability and average variance extracted.

\section{Table 1}

\section{Factor Loading}

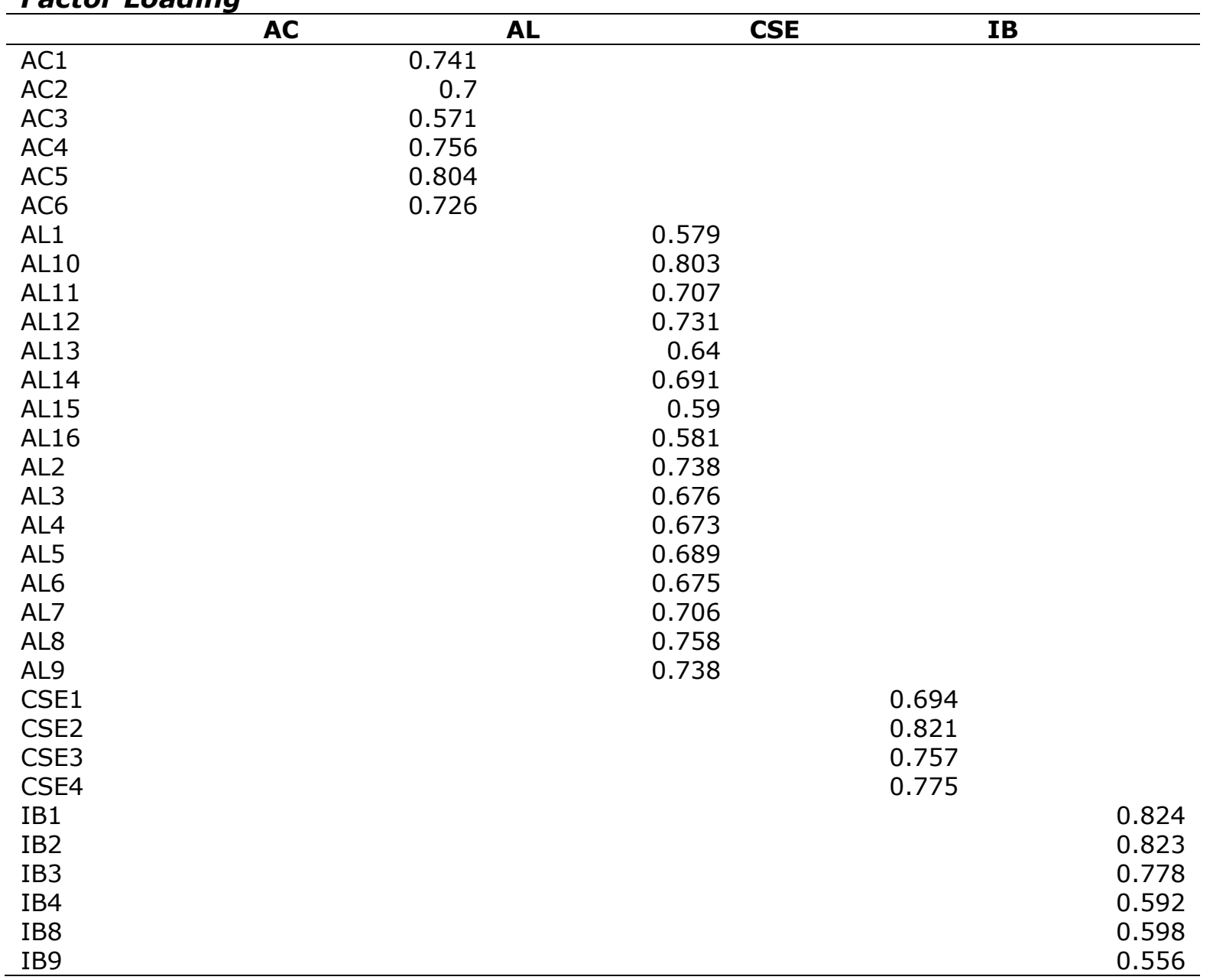

Note: Affective Commitment (AC), Authentic Leadership (AL), Creative Self-efficacy (CSE), Innovative Behaviour (IB) 
The Cronbach alpha must remain higher than 0.70 for minimum acceptability, more than 0.80 considered as high reliability, higher than 0.90 Cronbach alpha demonstrates the excellent reliability. Similarly, the composite reliability is considered as acceptable when reported higher than 0.70 on measurement model assessment. The average variance extracted (AVE) should remain higher than 0.50 for acceptability of validity (Hair Jr et al., 2021). The table 1 below presents the outer-loading, the minimum acceptable loading must remain higher than 0.50 as suggested by (Hair, Sarstedt, Ringle, \& Mena, 2012).

The above tale demonstrated the factor loading of all items of each variable that meet the criteria of acceptability, so therefore, it is appropriate to assess the next phase of analysis to determine the Cronbach alpha, CR and AVE. The table 2 presents the values for Cronbach alpha, CR and AVE

\section{Table 2}

Cronbach Alpha, CR and AVE

\begin{tabular}{|c|c|c|c|}
\hline & Cronbach's Alpha & & \\
\hline $\mathrm{AC}$ & 0.812 & 0.865 & 0.519 \\
\hline $\mathrm{AL}$ & 0.925 & 0.935 & 0.574 \\
\hline CSE & 0.761 & 0.847 & 0.582 \\
\hline IB & 0.766 & 0.707 & 0.535 \\
\hline
\end{tabular}

Note: Affective Commitment (AC), Authentic Leadership (AL), Creative Self-efficacy (CSE), Innovative Behaviour (IB)

The above table demonstrated the values of Cronbach alpha, CR and AVE, the construct Affective Commitment $(A C)$ has been reported good reliability as 0.812 , the alpha for authentic leadership was reported as 0.925 , for creative self-efficacy was reported as 0.761 and for innovative behaviour the Cronbach alpha was reported as 0.766 that meets the criteria for acceptable value of Cronbach alpha. The composite reliability is also presented in the table and reported for each construct AC, AL, CSE and IB as 0.865, 0.935, 0.847 and 0.707 respectively. The AVE for each construct also found to be acceptable as affective commitment was reported as 0.519 , for authentic leadership it was reported as 0.574 , for creative self-efficacy it is observed as 0.582 and innovative behaviour was reported as 0.535 that meets the requirement of AVE and acceptable validity of all constructs.

\subsection{Discriminant Validity}

The discriminant validity is also assessed in measurement model, the square root of AVE must remain higher than correlation values of other constructs of the study as per suggested criteria by (Fornell \& Larcker, 1981). The table 3 presents the discriminant validity of all constructs.

Table 3

Discriminant Validity

\begin{tabular}{lrrrrr}
\hline & AC & AL & CSE & \multicolumn{2}{c}{ IB } \\
\hline AC & 0.720 & & & & \\
AL & 0.681 & 0.758 & & \\
CSE & 0.664 & 0.627 & 0.763 & 0.731 \\
IB & 0.476 & 0.582 & 0.512 & 0.72
\end{tabular}

Note: Affective Commitment (AC), Authentic Leadership (AL), Creative Self-efficacy (CSE), Innovative Behaviour (IB)

The above table demonstrated the square root of AVE in comparison with correlational values of other construct, as per suggested criteria the square root of AVE of affective commitment found to be higher than other correlational values of same column, the affective commitment found to be 0.720 that is higher than other correlational values of the construct, similarly, the authentic leadership has higher square root of AVE as 0.758 as compare to other correlational values, the creative self-efficacy has higher square root of AVE as 0.763 and similarly the IB has 0.731 square root of AVE that satisfies the given criteria for acceptable discriminant validity. 


\subsection{Structural Equation Model (SEM)}

This section entails the assessment of direct hypotheses, the bootstrapping method of Smart-PLS is utilized for investigating the direct relationship. The significance of relationship is assessed on the base of $\beta$ value, t-statistics and $p$-value, the $\beta$ shows the strength and direction of the relationship, $t$-value presents the significance of the relationship as t-value must remain higher than 1.96 , and $\mathrm{p}$-value must remain lower than 0.05 as confidence interval is $95 \%$ in social sciences (Hair et al., 2012). The table 4 demonstrates the direct relationship investigation and figure 2 presents the structural equation model (SEM) developed in Smart-PLS.

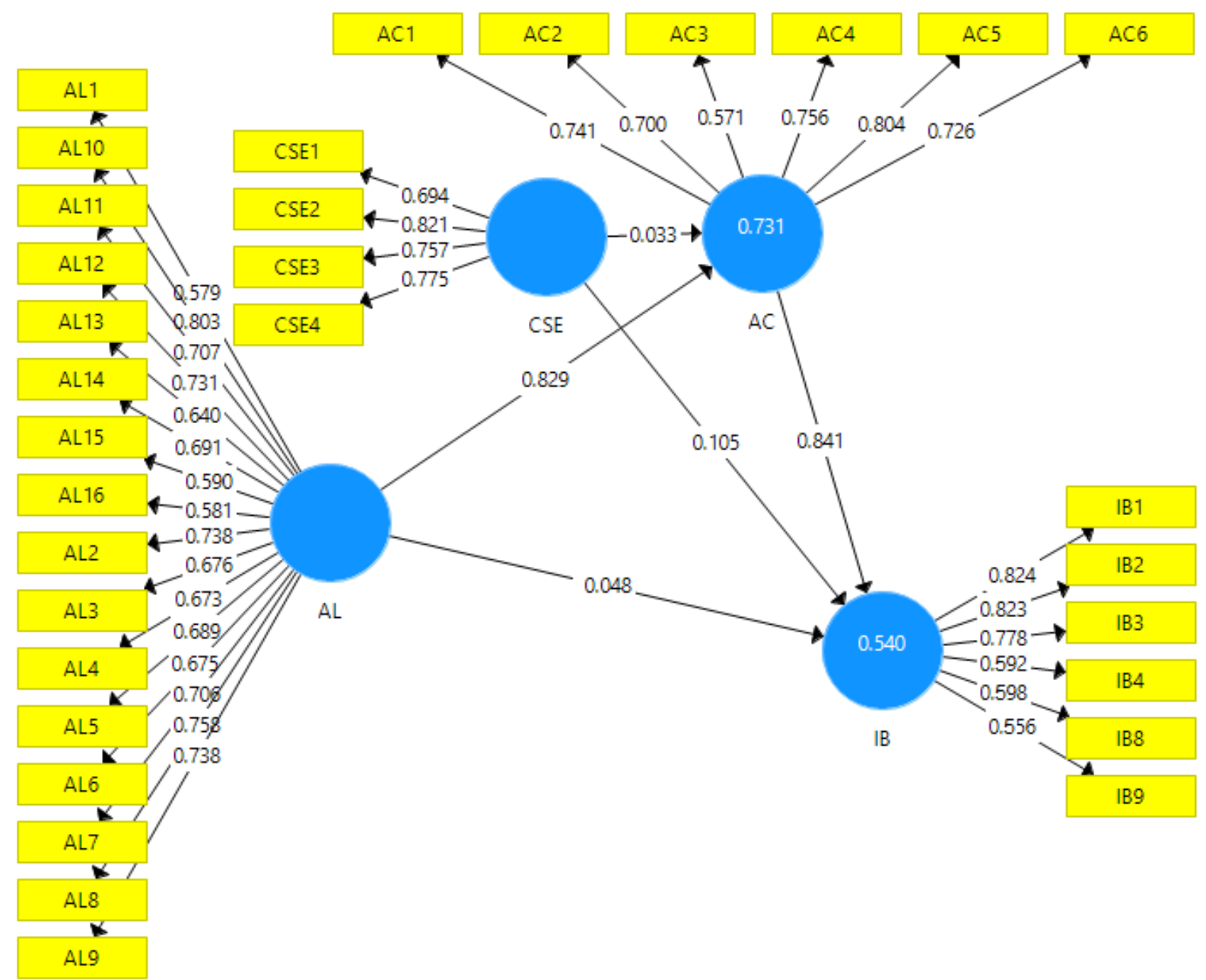

\section{Figure 2: Structural equation model (SEM)}

Note: Affective Commitment $(A C)$, Authentic Leadership ( $A L)$, Creative Self-efficacy (CSE), Innovative Behaviour (IB)

Table 4

Direct Relationship

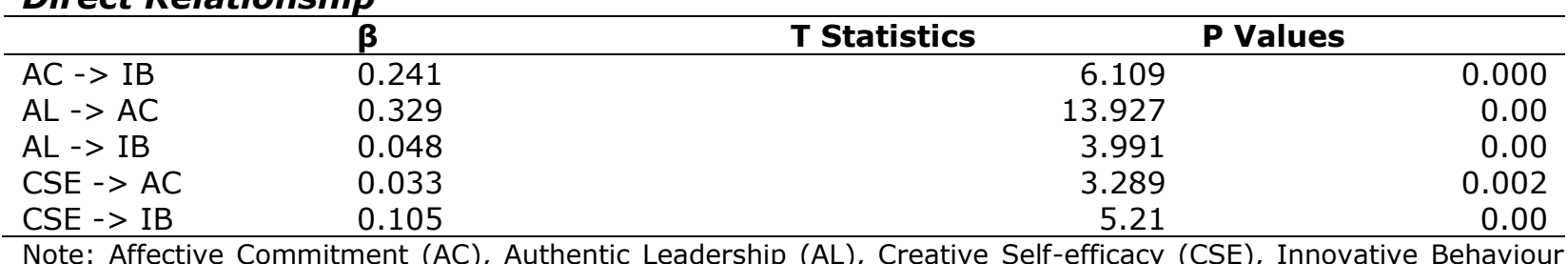

(IB)

Hypothesis H1: Affective Commitment influence the Innovative behavior among employees of higher education sector of Pakistan 
The results of the hypothesis $\mathrm{H} 1$ show that $(\beta=0.241, \mathrm{t}$-value $=6.109, \mathrm{p}$-value $=$ $0.000)$, this means affective commitment influence the innovative behavior among the respondents of the study. The results of the study depicted that affective commitment significantly influences the behavior of employees, the current study incorporated the academic employees of the higher education sector and it has been found that higher the affective commitment, the higher the positive behavioral outcomes, such as innovative behavior. The results of the study found to be inline and verifies the results of previous studies conducted by (Albrecht \& Marty, 2020; Khaola \& Coldwell, 2019; Nazir et al., 2018).

Hypothesis H2: Creative Self-efficacy influence the Innovative behavior among employees of higher education sector of Pakistan

The creative self-efficacy found to be influential towards innovative behavior, the prior literature argues that self-efficacy has tendency to impact the behavior of employees. The results of the current study show that $(\beta=0.105, t$-value $=5.210, p$-value $=0.000)$, this means relationship between creative self-efficacy has significance on the base of $t-$ value that reported as 5.210 with $p$-value as 0.000 that satisfies conditions of the significance, so therefore the hypothesis $\mathrm{H} 2$ accepted on statistical grounds. The results of the present research depict that creative self-efficacy influence the positive behavioral outcomes of the employees. The employees of higher education having creative selfefficacy must be able to innovate and to take initiatives to become more productive. The result of the current study found to be in line with prior literature and verifies the findings that creative self-efficacy has the tendency to influence the behavior of employees (Abdullah et al., 2017; AlMazrouei \& Zacca, 2020; Newman et al., 2018).

Hypothesis H3: Authentic Leadership influence the Innovative behavior among employees of higher education sector of Pakistan

The hypothesis $\mathrm{H} 3$ investigates the relationship between authentic relationship and innovative behavior, that means the leadership has the strong influence on behavior of employees. The authentic relationship has the tendency to influence the workplace environment and behavior, the results of the present study show that $(\beta=0.048, t$-value $=$ $3.991, \mathrm{p}$-value $=0.000$ ), that means authentic leadership influence the behavior of employees, the relationship found to be significant on statistical grounds. The result of the current study depicts that authentic leadership at higher education sector Pakistan is required in order to gain the competitive advantage and to perform better by influencing and shaping the behavior of employees. The prior literature reported similar findings that authentic leadership influence the positive behavioral outcomes (Ibusa, Wahabb, Ismailc, \& Omard, 2020b; S. K. Khan, Memon, \& Ramayah, 2018; Qi et al., 2019).

Hypothesis H4: Creative Self-Efficacy influence the Affective Commitment among employees of higher education sector of Pakistan

The hypothesis $\mathrm{H} 4$ investigates the relationship between creative self-efficacy and affective commitment, the literature argues that creative self-efficacy influences the behavior of employees. The result of current study shows that $(\beta=0.033$, $t$-value $=3.289$, $p$-value $=0.002$ ) this means creative self-efficacy of an employee increase the innovative initiatives and shape the behavior towards being innovative. The prior literature also reported that creative self-efficacy has the tendency to influence the behavior of employees and findings of the current research found to be in line with prior literature (Almutairi, 2020; Çetin \& Aşkun, 2018; Lent et al., 2017).

Hypothesis H5: Authentic Leadership influence the Affective Commitment among employees of higher education sector of Pakistan

The hypothesis $\mathrm{H} 5$ investigates the relationship between authentic leadership and affective commitment, this means that authentic leadership is influential for gaining the commitment of employees, the effectiveness of the leadership brings number of benefits to the organizations. The results of the study depicted that $(\beta=0.329, \mathrm{t}$-value $=13.927, \mathrm{p}$ value $=0.000)$, this means authentic leadership influence the commitment level of the employees. The findings of the current study found to be in line with prior literature that 
also posited that authentic leadership influence the commitment level of the employees (Allen-Ile et al., 2020; Ribeiro et al., 2020; Walumbwa et al., 2008).

\section{Indirect Relationship}

The study incorporated the investigation of mediating relationship between exogenous and endogenous constructs, the mediating influence of affective commitment is determined between creative self-efficacy and innovative behavior, and between authentic leadership and innovative behavior. The table 5 presents the indirect relationship investigation results.

\section{Table 5}

\section{Indirect hypotheses testing}

\begin{tabular}{lllll}
\hline & $\boldsymbol{\beta}$ & T Statistics & \multicolumn{2}{c}{ P Values } \\
\hline AL -> AC - > IB & & 0.697 & 5.368 & 0.000 \\
CSE -> AC -> IB & & 0.028 & 0.461 & 0.645 \\
\hline
\end{tabular}

Note: Affective Commitment (AC), Authentic Leadership (AL), Creative Self-efficacy (CSE), Innovative Behaviour (IB)

The above table demonstrated the mediating role of affective commitment between independent and dependent variables that is assessed on the base of $\beta$ value, $t$-value and p-value.

Hypothesis H6: Affective Commitment mediates the relationship between creative selfefficacy and Innovative behavior among employees of higher education sector of Pakistan

The hypothesis $\mathrm{H} 6$ investigates the mediating role of affective commitment between creative self-efficacy and innovative behavior, the results of the study depicted that ( $\beta=$ 0.028 , t-value $=0.461, \mathrm{p}$-value $=0.645)$, based on the values the mediation is not reported as the t-value found to be lower than cutoff point of 1.96 , this means the affective commitment do not mediate the relationship between creative self-efficacy and innovative behavior. The results of the study found to be contradictory with prior literature that found significant mediation of affective commitment (Mercurio, 2015; Tahir et al., 2021).

Hypothesis H7: Affective Commitment mediates the relationship between authentic leadership and Innovative behavior among employees of higher education sector of Pakistan

The hypothesis $\mathrm{H} 7$ investigated the mediating role of affective commitment between authentic leadership and innovative behavior, the results depicted that $(\beta=0.697$, t-value $=5.368, \mathrm{p}$-value $=0.000$ ), this shows significant mediation role is reported by affective between independent and dependent variables. This means that authentic leadership influence the affective commitment that further impact the behavior of employees to be innovative, the findings encourage to have effective leadership in order to gain the required behavioral outcomes of the employees.

\section{Conclusion}

The central purpose of the research is to determine the innovative behaviour of employees at higher education sector of Pakistan, the predictors of innovative behaviour including creative self-efficacy and authentic leadership with the mediating role of affective commitment has been incorporated in the study. The study examined the empirical relationship between creative self-efficacy and affective commitment, authentic leadership and affective commitment, creative self-efficacy and innovative behaviour, authentic leadership and innovative behaviour and between affective commitment and innovative behaviour. The simple random sampling was utilized for data collection and Smart-PLS was utilized for data analysis. The findings of the study depicted that affective commitment is predicted by creative self-efficacy and authentic leadership, and affective commitment influence the innovative behaviour. The creative self-efficacy and authentic leadership influence the innovative behaviour, meanwhile significant mediation role of affective commitment is evident between authentic leadership and innovative behaviour, however no 
mediation was found between creative self-efficacy and innovative behaviour by affective commitment and reported insignificant. The hypothesis $\mathrm{H} 1$ was significant that shows affective commitment influence the innovative behaviour, the hypothesis $\mathrm{H} 2$ found to be significant as creative self-efficacy influence the innovative behaviour, the hypothesis $\mathrm{H} 3$ also reported as significant that authentic leadership influence the innovative behaviour, the hypothesis $\mathrm{H} 4$ also significant that creative self-efficacy influence the affective commitment, the hypothesis $\mathrm{H} 5$ also found to be significant that authentic leadership influence the affective commitment. The hypothesis $\mathrm{H} 6$ was insignificant that no mediation was reported between creative self-efficacy and innovative behaviour by affective commitment, but hypothesis $\mathrm{H} 7$ was significant that affective commitment mediated the relationship between authentic leadership and innovative behaviour. The study suggested to university management to ensure the innovative capabilities among employees, and suitable knowledge, skills and abilities must be ensured in order to enhance the innovative capabilities. There is need to gain the commitment of employees through effective leadership and necessary skill set to enhance the innovative initiatives at higher education sector.

\section{References}

Abdullah, M. I., Ashraf, S., \& Sarfraz, M. (2017). The organizational identification perspective of CSR on creative performance: The moderating role of creative selfefficacy. Sustainability, 9(11), 2125.

Afsar, B., \& Masood, M. (2018). Transformational leadership, creative self-efficacy, trust in supervisor, uncertainty avoidance, and innovative work behavior of nurses. The Journal of Applied Behavioral Science, 54(1), 36-61.

Ahmad, R., Ahmad, S., Islam, T., \& Kaleem, A. (2020). The nexus of corporate social responsibility (CSR), affective commitment and organisational citizenship behaviour in academia. Employee Relations: The International Journal.

Ahmed, S., \& Ahmed, A. (2015). Employee innovation: management practices affecting the innovative behavior at workplace. Paper presented at the 3rd Islamic Countries Conference on Statistical Sciences (ICCS-13): Statistics for Better Life.

Al-Husseini, S., El Beltagi, I., \& Moizer, J. (2019). Transformational leadership and innovation: the mediating role of knowledge sharing amongst higher education faculty. International Journal of Leadership in Education, 24(5), 670-693.

Al-Husseini, S. J., \& Dosa, T. A. (2016). The effects of transformational leadership on process innovation through knowledge sharing. International Journal of Economics and Management Engineering, 10(8), 2752-2759.

Albrecht, S. L., \& Marty, A. (2020). Personality, self-efficacy and job resources and their associations with employee engagement, affective commitment and turnover intentions. The International Journal of Human Resource Management, 31(5), 657681.

Allen-Ile, C., Mahembe, B., \& Balogun, T. V. (2020). A confirmatory factor analytic study of an authentic leadership measure in Nigeria. SA Journal of Human Resource Management, 18(1), 1-9.

AlMazrouei, H., \& Zacca, R. (2020). Cultural intelligence as a predictor of expatriate managers turnover intention and creative self-efficacy. International Journal of Organizational Analysis.

Almutairi, Y. M. N. (2020). Leadership self-efficacy and organizational commitment of faculty members: higher education. Administrative Sciences, 10(3), 66.

Alshammari, M. (2015). Corporate social responsibility and firm performance: The moderating role of reputation and institutional investors. International Journal of Business and Management, 10(6), 15.

Bandura, A., Freeman, W., \& Lightsey, R. (1999). Self-efficacy: The exercise of control. In: Springer.

Bawuro, F. A., Shamsuddin, A., Wahab, E., El-Nafaty, A. S. i., Bashir, F. M., \& Moveh, L. P. (2020). THE LINKAGE BETWEEN MOTIVATIONAL MECHANISMS AND TEACHERS'INNOVATIVE BEHAVIOR: A MULTIPLE REGRESSION ANALYSIS. Journal of Critical Reviews, 7(11), 2020.

Cai, W., Lysova, E. I., Khapova, S. N., \& Bossink, B. A. (2019). Does entrepreneurial leadership foster creativity among employees and teams? The mediating role of creative efficacy beliefs. Journal of Business and Psychology, 34(2), 203-217. 
Çetin, F., \& Aşkun, D. (2018). The effect of occupational self-efficacy on work performance through intrinsic work motivation. Management Research Review.

Darwish, T. K., Zeng, J., Rezaei Zadeh, M., \& Haak-Saheem, W. (2020). Organizational learning of absorptive capacity and innovation: Does leadership matter? European Management Review, 17(1), 83-100.

Devloo, T., Anseel, F., De Beuckelaer, A., \& Salanova, M. (2015). Keep the fire burning: Reciprocal gains of basic need satisfaction, intrinsic motivation and innovative work behaviour. European Journal of Work and Organizational Psychology, 24(4), 491504.

Elrehail, H., Emeagwali, O. L., Alsaad, A., \& Alzghoul, A. (2018). The impact of transformational and authentic leadership on innovation in higher education: The contingent role of knowledge sharing. Telematics and Informatics, 35(1), 55-67.

Erum, H., Abid, G., Contreras, F., \& Islam, T. (2020). Role of family motivation, workplace civility and self-efficacy in developing affective commitment and organizational citizenship behavior. European Journal of Investigation in Health, Psychology and Education, 10(1), 358-374.

Fornell, C., \& Larcker, D. F. (1981). Structural equation models with unobservable variables and measurement error: Algebra and statistics. In: Sage Publications Sage CA: Los Angeles, CA.

Fu, H., Ye, B. H., \& Law, R. (2014). You do well and I do well? The behavioral consequences of corporate social responsibility. International Journal of Hospitality Management, $40,62-70$.

Fullwood, R., Rowley, J., \& Delbridge, R. (2013). Knowledge sharing amongst academics in UK universities. Journal of knowledge management.

Gaspar, D., \& Mabic, M. (2015). Creativity in Higher Education. Universal Journal of Educational Research, 3(9), 598-605.

Hair, J. F., Sarstedt, M., Ringle, C. M., \& Mena, J. A. (2012). An assessment of the use of partial least squares structural equation modeling in marketing research. Journal of the academy of marketing science, 40(3), 414-433.

Hair Jr, J. F., Hult, G. T. M., Ringle, C. M., Sarstedt, M., Danks, N. P., \& Ray, S. (2021). Partial Least Squares Structural Equation Modeling (PLS-SEM) Using R: A Workbook. In: Springer Nature.

Ibusa, S., Wahabb, E., Ismailc, F., \& Omard, R. (2020a). Stimulating Innovative Work Behavior among Academics in Private Higher Educational Institutions. International Journal of Innovation, Creativity and Change, 11(4), 245-261.

Ibusa, S., Wahabb, E., Ismailc, F., \& Omard, R. (2020b). Stimulating Innovative Work Behavior among Academics in Private Higher Educational Institutions.

Ja'afaru Bambale, A. (2014). Relationship between servant leadership and organizational citizenship behaviors: Review of literature and future research directions. Journal of Marketing \& Management, 5(1).

Janssen, O. (2000). Job demands, perceptions of effort-reward fairness and innovative work behaviour. Journal of occupational and organizational psychology, 73(3), 287-302.

Javed, B., Khan, A. K., \& Quratulain, S. (2018). Inclusive leadership and innovative work behavior: examination of LMX perspective in small capitalized textile firms. The Journal of psychology, 152(8), 594-612.

Jia, X., Chen, J., Mei, L., \& Wu, Q. (2018). How leadership matters in organizational innovation: a perspective of openness. Management Decision.

Johnson, R. B., Onwuegbuzie, A. J., \& Turner, L. A. (2007). Toward a definition of mixed methods research. Journal of mixed methods research, 1(2), 112-133.

Karatepe, O. M., Aboramadan, M., \& Dahleez, K. A. (2020). Does climate for creativity mediate the impact of servant leadership on management innovation and innovative behavior in the hotel industry? International Journal of Contemporary Hospitality Management.

Kaur, K. D., \& Gupta, V. (2016). The impact of personal characteristics on innovative work behaviour: An exploration into innovation and its determinants amongst teachers. The International Journal of Indian Psychology, 3(3), 158-172.

Khalid, K. (2020). The Impact of Managerial Support on the Association Between Pay Satisfaction, Continuance and Affective Commitment, and Employee Task Performance. SAGE Open, 10(1), 2158244020914591. 
Khan, M. A., Ismail, F. B., Hussain, A., \& Alghazali, B. (2020). The interplay of leadership styles, innovative work behavior, organizational culture, and organizational citizenship behavior. Sage Open, 10(1), 2158244019898264.

Khan, S. K., Memon, M. A., \& Ramayah, T. (2018). Leadership and innovative culture influence on organisational citizenship behaviour and affective commitment: The mediating role of interactional justice. International journal of business and society, 19(3), 725-747.

Khaola, P., \& Coldwell, D. (2019). Explaining how leadership and justice influence employee innovative behaviours. European Journal of Innovation Management.

Krejcie, R. V., \& Morgan, D. W. (1970). Determining sample size for research activities. Educational and psychological measurement, 30(3), 607-610.

Lent, R. W., Ireland, G. W., Penn, L. T., Morris, T. R., \& Sappington, R. (2017). Sources of self-efficacy and outcome expectations for career exploration and decision-making: A test of the social cognitive model of career self-management. Journal of vocational behavior, 99, 107-117.

Mehmood, M. S., Jian, Z., \& Gilal, F. G. (2020). Entrepreneurial leadership and employee innovative behavior: Intervening role of creative self-efficacy. Human Systems Management, 39(3), 367-379.

Mehmood, N., Ungku, U. N. B., Irum, S., \& Ashfaq, M. (2016). Job satisfaction, affective commitment, and turnover intentions among front desk staff: Evidence from Pakistan. International Review of Management and Marketing, 6(4S).

Mercurio, Z. A. (2015). Affective commitment as a core essence of organizational commitment: An integrative literature review. Human Resource Development Review, 14(4), 389-414.

Meyer, J. P., Stanley, D. J., Herscovitch, L., \& Topolnytsky, L. (2002). Affective, continuance, and normative commitment to the organization: A meta-analysis of antecedents, correlates, and consequences. Journal of Vocational Behavior, 61(1), 20-52.

Naqshbandi, M. M., \& Tabche, I. (2018). The interplay of leadership, absorptive capacity, and organizational learning culture in open innovation: Testing a moderated mediation model. Technological Forecasting and Social Change, 133, 156-167.

Nardo, R., Evanita, S., \& Syahrizal, S. (2019). The Effect of Transformational Leadership and Non Physical Work Environment on Innovative Behavior with Work Motivation as a Mediation For Employees of Tour And Travel Companies In West Sumatera. Paper presented at the 2nd Padang International Conference on Education, Economics, Business and Accounting (PICEEBA-2 2018).

Nazir, S., Qun, W., Hui, L., \& Shafi, A. (2018). Influence of social exchange relationships on affective commitment and innovative behavior: Role of perceived organizational support. Sustainability, 10(12), 4418.

Nazir, S., Shafi, A., Atif, M. M., Qun, W., \& Abdullah, S. M. (2019). How organization justice and perceived organizational support facilitate employees' innovative behavior at work. Employee Relations: The International Journal.

Newman, A., Herman, H., Schwarz, G., \& Nielsen, I. (2018). The effects of employees' creative self-efficacy on innovative behavior: The role of entrepreneurial leadership. Journal of Business Research, 89, 1-9.

Paillé, P. (2009). The relationship between support, commitment and intent to leave team. Team Performance Management: An International Journal.

Qi, L., Liu, B., Wei, X., \& Hu, Y. (2019). Impact of inclusive leadership on employee innovative behavior: Perceived organizational support as a mediator. PloS one, 14(2), e0212091.

Rahoo, L. A., Baladi, Z. H., Yasmeen, T., Khan, M. A., \& Bhutto, A. (2020). The Impact of Knowledge Management on Creativity of Library Professionals in Public Sector Universities of Pakistan.

Rego, A., Vitória, A., Magalhães, A., Ribeiro, N., \& e Cunha, M. P. (2013). Are authentic leaders associated with more virtuous, committed and potent teams? The leadership quarterly, 24(1), 61-79.

Ribeiro, N., Duarte, A. P., Filipe, R., \& Torres de Oliveira, R. (2020). How authentic leadership promotes individual creativity: The mediating role of affective commitment. Journal of Leadership \& Organizational Studies, 27(2), 189-202.

Ribeiro, N., Gomes, D., \& Kurian, S. (2018). Authentic leadership and performance: the mediating role of employees' affective commitment. Social Responsibility Journal. 
Scott, S. G., \& Bruce, R. A. (1994). Determinants of innovative behavior: A path model of individual innovation in the workplace. Academy of management journal, 37(3), 580-607.

Semedo, A. S., Coelho, A., \& Ribeiro, N. (2019). Authentic leadership, happiness at work and affective commitment: An empirical study in Cape Verde. European Business Review.

Semedo, A. S. D., Coelho, A. F. M., \& Ribeiro, N. M. P. (2016). Effects of authentic leadership, affective commitment and job resourcefulness on employees' creativity and individual performance. Leadership \& Organization Development Journal.

Sönmez, B., \& Yıldırım, A. (2019). The mediating role of autonomy in the effect of proinnovation climate and supervisor supportiveness on innovative behavior of nurses. European Journal of Innovation Management.

Tahir, M., Hadi, N., \& Awan, T. (2021). The Role of Person-Organisation Fit and Affective Commitment in Inspiring Citizenship Behaviours among Banking Sector Employees of Pakistan. International Journal of Innovation, Creativity and Change, 15(6), 1-25.

Tang, Y., Shao, Y.-F., \& Chen, Y.-J. (2019). Assessing the mediation mechanism of job satisfaction and organizational commitment on innovative behavior: the perspective of psychological capital. Frontiers in psychology, 10, 2699.

Walumbwa, F. O., Avolio, B. J., Gardner, W. L., Wernsing, T. S., \& Peterson, S. J. (2008). Authentic leadership: Development and validation of a theory-based measure. Journal of management, 34(1), 89-126.

Walumbwa, F. O., Cropanzano, R., \& Goldman, B. M. (2011). How leader-member exchange influences effective work behaviors: Social exchange and internal-external efficacy perspectives. Personnel psychology, 64(3), 739-770.

Zhou, W., \& Velamuri, V. K. (2018). Key contextual success factors for employee innovative behavior: A study in a foreign manufacturing subsidiary in China. Cogent Business \& Management, 5(1), 1471770.

Zhu, C. (2015). Organisational culture and technology-enhanced innovation in higher education. Technology, Pedagogy and Education, 24(1), 65-79. 